\section{Impact of COVID-19 on access to chronic kidney replacement therapy in the public sector of Westerin Cape Province, South Africa}

To the Editor: Since the start of the lockdown in South Africa (SA) on 27 March 2020, a decision was made to temporarily suspend living and deceased kidney donor transplant programmes in Western Cape Province because of concerns regarding the unknown consequences that COVID-19 might have in this vulnerable, immunocompromised population. In addition, the management of deceased potential donors was also stopped so that emergency departments and intensive care units could prioritise COVID19 patients. This decision was justified, as subsequent studies reported poor outcomes for both the kidney allograft and patient survival following COVID-19 infection, with reported mortality rates ranging from $20 \%$ to $28 \%$, greater than that reported for the general population. ${ }^{[1-3]}$

These changes, however, have had a knock-on effect on the number of new patients with end-stage kidney disease accepted for chronic kidney replacement therapy (KRT) in the public sector. The cost of dialysis therapy is exorbitant and ranges from $\sim$ ZAR350 000 to ZAR450 000 per patient per annum in the public sector, depending on the dialysis modality. ${ }^{[4]}$ As a result, access to KRT in the public sector is limited and therefore needs to be rationed. ${ }^{[5]}$

The availability of dialysis slots is determined by the number of kidney transplants performed and the mortality rate of KRT patients awaiting transplantation. Since the annual mortality of dialysis patients is $\sim 10 \%$ in both the public and the private sector, ${ }^{[6]}$ the availability of dialysis slots is mainly dependent on transplantation. The public sector in the Western Cape performs an average of 50 kidney transplants per year. ${ }^{[7]}$ As can be seen in Fig. 1, there was a sharp decline in the number of kidney transplants for the period 1 August 2020 to 31 July 2021; however, this was offset by $\sim 20$ COVID-19-related excess deaths in KRT patients. Since access to KRT was already limited before the COVID-19 pandemic, there has been tremendous pressure on public sector facilities to assist with KRT.

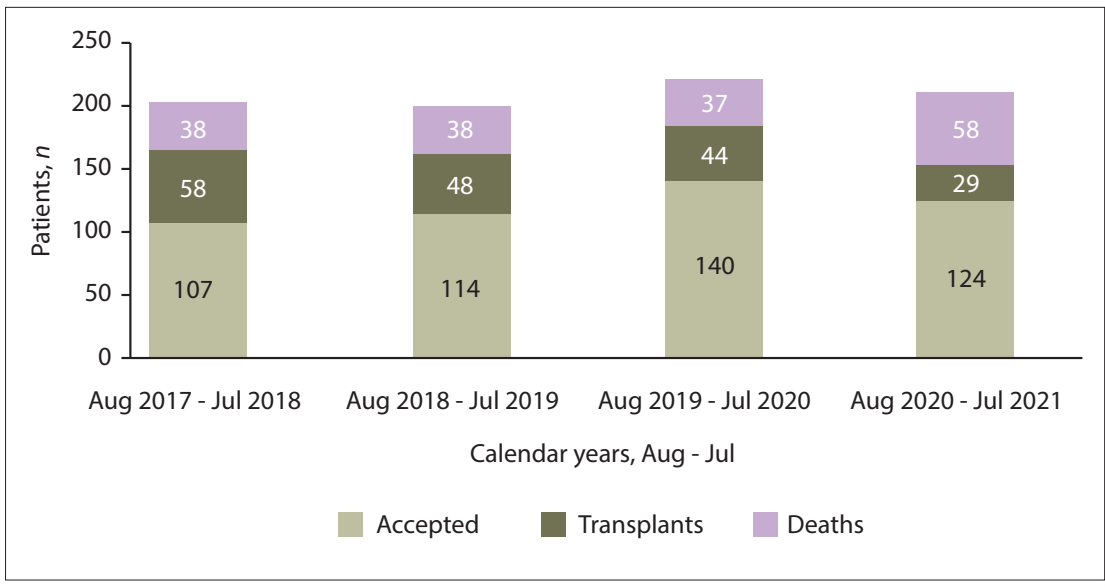

Fig. 1. Comparison of the number of patients accepted for chronic kidney replacement therapy, number of kidney transplants and deaths for the past 4 calendar years. The number of patients is the combined totals of all adult patients accepted and treated at Tygerberg Hospital and Groote Schuur Hospital, Cape Town, South Africa.

The Council for Medical Schemes Annual Report $^{[8]}$ indicates that only $16 \%$ of the SA population currently have medical insurance. Most South Africans are therefore dependent on the public healthcare sector; however, this may soon be compounded by an increase in the pool of patients seeking treatment from the public sector as a result of increased unemployment rates caused by the COVID-19 pandemic.

In the most recent review of the prioritysetting approach to patients requiring KRT in the Western Cape, it was found that we are providing services to only $7.8 \%$ of those who require it, down from $12.5 \% 5$ years ago. ${ }^{[5]}$ The severe bottleneck created by the lack of transplantation during the pandemic, combined with the lack of increased dialysis services, is creating an untenable situation for nephrologists and their patients. We urge all role-players in the state medical services to actively help relieve this pressure by increasing theatre time and services allocated to transplantation, increasing and marketing vaccine availability to all patients on dialysis, and substantially increasing the patient capacity we are allowed to support in state facilities.

\section{Mogamat-Yazied Chothia}

Division of Nephrology, Department of Medicine, Faculty of Medicine and Health Sciences, Stellenbosch University and Tygerberg Hospital, Cape Town, South Africa yaziedc@sun.ac.za

\section{Zunaid Barday}

Division of Nephrology and Hypertension, Department of Medicine, Faculty of Health Sciences, University of Cape Town and Groote Schuur Hospital, Cape Town, South Africa

\section{Johan Nel, Mogamat Razeen Davids}

Division of Nephrology, Department of Medicine, Faculty of Medicine and Health Sciences, Stellenbosch University and Tygerberg Hospital, Cape Town, South Africa

1. Elias M, Pievani D, Randoux C, et al. COVID-19 infection in kidney transplant recipients: Disease incidence and clinical outcomes. J Am Soc Nephrol 2020;31(10):2413-2423. https:/ doi.org/10.1681/asn.2020050639

2. Akalin E, Azzi Y, Bartash R, et al. Covid-19 and kidney transplantation. N Engl J Med 2020;382(25):2475-2477. https:// dranslantation. N Engl J Med 200

3. Jones ES, Davidson BJ, Barday Z, et al. COVID-19 and the kidney: A South African state healthcare experience. Clin kephrol 2021;95:171-181. https://doi.org/10.5414/cn110390 Nephrol 2021;95:171-181. https://doi.org/ $10.5414 / \mathrm{cn} 110390$
4. Davies M, Cassimjee Z. Provision of long-term renal replacement therapy to non-national patients in South Africa. S Afr Med J 2021;111(7):615-619. https://doi.org/10.7196/ SAMJ.2021.v111i7.15395

5. Moosa MR, Maree JD, Chirehwa MT, Benatar SR. Use of the 'accountability for reasonableness' approach to improve ONE 2016;11(10):e0164201. https://doi.org/10.1371/journal. pone. 0164201

6. Jardine T, Wong E, Steenkamp R, Caskey FJ, Davids MR Survival of South African patients on renal replacement therapy. Clin Kidney J 2020:13(5):782-790. https//doiceners the 1093/ck/ rg/10.1093/ckj sfaa012

7. Davids MR, Jardine T, Marais N, Zunza M, Jacobs JC, Sebastian S. South African Renal Registry Annual Report 2017. Afr Nephrol 2019;22(1):60-71. https://doi.org/10.21804/22-1-3810 8. Council for Medical Schemes. Council for Medical Scheme Annual Report 2019/20. https://www.medicalschemes.co.za/ annualreport2020/ (accessed 6 September 2021). org/10.7196/SAMJ.2021.v111i11.16113 fairness in accessing dialysis in a middle-income country. PLoS

S Afr Med J 2021;111(11):1030. https://doi. 